\title{
Wybrane aspekty psychospołecznego funkcjonowania oraz skuteczność terapii poznawczo-behawioralnej u osób cierpiących z powodu szumów usznych
}

\section{Selected aspects of psychosocial functioning and the effectiveness of cognitive-behavioral therapy for people suffering from tinnitus}

\author{
Agnieszka Kubińska ${ }^{1,2}$ \\ ${ }^{1}$ Instytut Fizjologii i Patologii Słuchu, Światowe Centrum Słuchu, Zespół ds. Realizacji i Obsługi Projektów, \\ Warszawa/Kajetany \\ ${ }^{2}$ Instytut Fizjologii i Patologii Słuchu, Światowe Centrum Słuchu, Zakład Szumów Usznych, Warszawa/Kajetany \\ Adres autora: Agnieszka Kubińska, Światowe Centrum Słuchu, ul. Mokra 17, Kajetany, 05-830 Nadarzyn, \\ e-mail: a.kubinska@ifps.org.pl
}

\begin{abstract}
Streszczenie
Szumy uszne (łac. tinnitus) opisywane są jako odczucie słyszenia dźwięku przy braku pobudzenia zewnętrznego. U części osób ich doświadczających wrażenie to jest na tyle dokuczliwe, że powoduje zaburzenia w codziennym funkcjonowaniu. Osoby cierpiące z powodu szumów usznych częściej doświadczają depresji, lęku, stresu, zaburzeń sfery poznawczej czy bezsenności. Dokuczliwe szumy uszne mogą powodować zakłócenia w pracy zawodowej, życiu towarzyskim czy spędzaniu czasu wolnego. Aby wspierać osoby doświadczające dużej dokuczliwości szumów usznych, proponuje się im różne rodzaje interwencji psychologicznych. Najczęstszą i najszerzej opisaną jest terapia poznawczo-behawioralna. Przegląd wyników badań pokazuje, że zazwyczaj jest to skuteczna forma terapii psychologicznej stosowana wobec osób cierpiących z powodu szumów usznych.
\end{abstract}

Celem niniejszego artykułu jest omówienie wybranych aspektów psychospołecznego funkcjonowania oraz przegląd badań nad skutecznością terapii poznawczo-behawioralnej u osób cierpiących z powodu szumów usznych.

Słowa kluczowe: szumy uszne • jakość życia • stres • depresja • lęk • terapia poznawczo-behawioralna

\begin{abstract}
Tinnitus is described as the sensation of hearing sounds without any external stimulation. In some cases this feeling is so annoying that it may cause disturbances in daily functioning. People suffering from tinnitus often experience depression, anxiety, stress, cognitive disorders or insomnia. Annoying tinnitus may interfere with professional work, social life or holidays. In order to support people experiencing high annoyance of tinnitus, different types of psychological interventions may be offered. The most common and widely described is the cognitive-behavioral therapy. Results obtained by different research groups indicate that it is generally effective form of psychological therapy for people suffering from tinnitus.
\end{abstract}

The purpose of this article is to discuss selected aspects of psychosocial functioning and a review of the studies on the effectiveness of cognitive-behavioral therapy for people suffering from tinnitus.

Key words: tinnitus $\bullet$ quality of life $\bullet$ stress $\bullet$ depression $\bullet$ anxiety $\bullet$ cognitive-behavioral therapy

\section{Wstęp}

Szumy uszne (łac. tinnitus) opisywane są jako odczucie słyszenia dźwięku przy braku pobudzenia zewnętrznego. Odczuwalne są w jednym uchu, obojgu uszach lub wewnątrz głowy. Mogą występować pod postacią różnych dźwięków, takich jak: dzwonienie, świst, pisk, cykanie świerszczy, buczenie, brzęczenie lub ich kombinacje. Są słyszane stale lub okresowo. Przyjmuje się, że szumy uszne powstają na skutek nieprawidłowej aktywności nerwowej w obrębie dróg 
słuchowych, która w ośrodkach słuchowych błędnie rozpoznawana jest jako dźwięk [1].

Według niektórych autorów [2] pierwsze wzmianki o szumach usznych można spotkać w papirusie Ebersa, datowanym na lata $1650-1532$ p.n.e. Schorzenie to nazywano „zaczarowanym uchem”. Natomiast pierwszy niekwestionowany zapis dotyczący szumów usznych, jak przytacza Dietrich [3], można znaleźć w Corpus Hippocraticum Hipokratesa (460-377 p.n.e.), gdzie szumy uszne łączono z utratą słuchu, bólami głowy i zaburzeniami miesiączkowania.

Szumy uszne występują zarówno u dorosłych, jak i u dzieci $[4,5]$. Podaje się, że problem szumów usznych dotyczy $10 \%$ populacji w Wielkiej Brytanii, 14,2\% w Szwecji, 8,4\% w Stanach Zjednoczonych, 15,1\% w Norwegii [6]. Z badań przeprowadzonych w Polsce przez Instytut Fizjologii i Patologii Słuchu [5] na przełomie 1998 i 1999 roku wynika, że 20,1\% populacji (powyżej 17 r.ż.) odczuwa szumy uszne trwające powyżej 5 minut. Zauważono również, że częstotliwość występowania szumów usznych wzrasta wraz z wiekiem. Najwyższy odsetek występowania szumów usznych, wynoszący 52,8\%, zaobserwowano w populacji osób po 75 r.ż. Dla 13,8\% osób z szumami usznymi nie stanowią one żadnego problemu. Ponad połowa osób z szumami usznymi odczuwa je jako łagodne, a około $10 \%$ jako dokuczliwe [5].

Dla wielu osób szumy uszne są poważnym problemem, gdyż wpływają znacząco na jakość życia $[7,8]$. Osoby doświadczające dużej dokuczliwości szumów usznych częściej cierpią na depresję, zaburzenia lękowe, bezsenność, zaburzenia koncentracji uwagi. Odczuwają też większe nasilenie stresu czy emocji negatywnych np. irytacji [8-10]. Mają poczucie, że nie radzą sobie z szumami usznymi i ich dokuczliwością. Najczęstszą formą interwencji psychologicznej stosowanej u osób cierpiących z powodu szumów usznych jest terapia poznawczo-behawioralna.

Celem niniejszego artykułu jest omówienie wybranych aspektów funkcjonowania psychospołecznego oraz przegląd badań dotyczący skuteczności terapii poznawczo-behawioralnej u osób z szumami usznymi.

\section{Wybrane aspekty psychospołecznego funkcjonowania osób cierpiących z powodu szumów usznych}

Wciąż relatywnie mało wiemy, jakie czynniki - fizjologiczne, poznawcze, emocjonalne, behawioralne - przyczyniają się do odczuwania większej dokuczliwości szumów usznych. Wyniki badań Langebach i wsp. [11] wskazują, że doświadczanie początkowo nieprzyjemnych stanów związanych z szumami usznymi - odczuwanie ich jako uciążliwy czy bolesny stan, współwystępująca depresja, podwyższony poziom lęku, niezadowolenie z życia i zaburzenia snu - stanowi ważny predyktor w rozwoju cierpienia związanego z szumami usznymi. Na podstawie tych wyników badań autorzy twierdzą również, że u osób doświadczających stresu i stanu napięcia szumy uszne mogą rozwijać się w wyniku wzrostu napięcia psychofizycznego [11]. Heinecke i wsp. [12] sugerują, że proces dysfunkcyjnych ocen poznawczych, takich jak negatywne myśli na temat szumów usznych, może mieć bardzo istotny wpływ na doświadczany dyskomfort. $\mathrm{W}$ ich badaniach podczas testów w warunkach podwyższonego stresu osoby z szumami usznymi oceniały obciążenie fizjologiczne i psychiczne jako znacznie wyższe niż grupa kontrolna. Natomiast obiektywne miary poziomu pobudzenia (napięcie mięśni, przewodnictwo skórne) nie potwierdziły powyższych ocen.

Ponad połowa osób z szumami usznymi cierpi na różne zaburzenia natury psychicznej i emocjonalnej, a wśród nich najczęściej występują depresja i zaburzenia lękowe w różnej postaci [13]. Wśród problemów najczęściej zgłaszanych przez osoby z szumami usznymi wymienia się: emocjonalne napięcie, trudności w uzyskiwaniu rozluźnienia i odpoczynku, problemy ze snem, rozdrażnienie, zaburzenia sfery poznawczej i emocjonalnej $[9,14]$.

\section{Szumy uszne a stres}

Osoby cierpiące $\mathrm{z}$ powodu szumów usznych mają znacznie podwyższony poziom subiektywnie odczuwanego stresu [10]. Wyniki otrzymane w kwestionariuszu opisu symptomów depresji czy skali służącej do oceny objawów psychopatologii pokazują, że osoby te cierpią z powodu większej ilości dolegliwości natury psychicznej niż grupa kontrolna [12]. Przytaczane badania [12] wyraźnie wskazują, że pomimo subiektywnie odczuwanego wysokiego poziomu stresu, obiektywne miary (napięcie mięśni, przewodnictwo skórne) nie potwierdzają większego pobudzenia. Interesujący jest wynik reakcji na stresor w postaci słuchania własnych szumów. Analiza badań nie wykazała bardziej zintensyfikowanej reakcji stresowej u osób z szumami usznymi w odpowiedzi na słuchanie własnych szumów usznych, choć osoby te zgłaszały wyższy poziom subiektywnie odczuwanego stresu po ekspozycji na stresor niż grupa kontrolna. Zgłaszana trudność w uzyskiwaniu rozluźnienia i zdolności do wypoczynku w przypadku pomiaru obiektywnego również nie została wykazana [12]. Powyższe badania sugerują, że poznawcza ocena szumów usznych jako stresujące może być jednym z ważniejszych czynników moderujących dyskomfort.

\section{Szumy uszne a zaburzenia sfery poznawczej}

Szumy uszne mogą mieć wpływ na funkcje poznawcze, szczególnie na osłabienie selektywności i podzielności uwagi $[15,16]$. Badania pokazują [15], że osoby z szumami usznymi wypadają gorzej od grupy kontrolnej w zadaniach poznawczych, ale głównie w przypadku zadań złożonych (np. wykonywanie dwóch zadań poznawczych jednocześnie). W zadaniach łatwych, automatycznych, niewymagających większego skupienia uwagi i kontroli wypadają podobnie do osób bez szumów usznych. Rossiter i wsp. [16] zbadali również, że niektóre osoby z szumami usznymi mają trudności z koncentracją uwagi na zadaniu oraz ograniczoną zdolność do przechowywania i pobierania informacji z pamięci roboczej. Wydaje się, jak twierdzą autorzy [15], że jednym z mechanizmów wyjaśniających współwystępowanie chronicznych szumów usznych i upośledzenia funkcji poznawczych jest uwaga. Osoba z szumami usznymi podczas wykonywania zadań poznawczych dzieli swoją uwagę na szumy uszne i zadanie, co zwiększa wykorzystanie zasobów uwagi. 
Kolejnym aspektem sfery poznawczej, mającym związek z psychologicznym funkcjonowaniem osób z szumami usznymi, jest określony rodzaj myślenia. Mowa o myśleniu katastroficznym ${ }^{1}$, które pełni istotną funkcję w postrzeganiu większej dokuczliwości szumów usznych. Jest ono silnie skorelowane $\mathrm{z}$ symptomami depresji, poszukiwaniem profesjonalnej pomocy medycznej czy odczuwaniem subiektywnie wyższej głośności szumów usznych [17]. Myśli katastroficzne u osób z szumami usznymi mogą dotyczyć obawy, że głośność szumów wzrośnie, przyczynią się one do dalszej utraty słuchu, spowodują ciężką chorobę lub kolejne ograniczenia codziennej aktywności. Taki sposób myślenia może nasilać poznawcze i emocjonalne napięcie, a tym samym zmniejszać zdolność do akceptacji i habituacji szumów usznych [18-20]. Myśli katastroficzne i lęk z nimi związany są połączone ze zwiększoną uwagą towarzyszącą szumom usznym i mogą być jednym z kluczowych czynników powodujących utrzymywanie się szumów usznych i poczucia dyskomfortu [21].

\section{Szumy uszne a funkcjonowanie społeczne}

Szumy uszne mogą przyczyniać się do zmiany funkcjonowania w obszarze pracy zawodowej (powodując również absencje), prac domowych, spędzania czasu wolnego, aktywności fizycznej czy życia społecznego [7]. Osoby doświadczające szumów usznych i niedosłuchu mogą mieć też problem $\mathrm{z}$ rozumieniem mowy, komunikowaniem się $\mathrm{z}$ ludźmi, co może $\mathrm{z}$ kolei wpływać na ich funkcjonowanie społeczne, a w konsekwencji prowadzić do wycofywania się czy nawet izolacji [14,22].

\section{Szumy uszne a lęk i zaburzenia depresyjne}

Odczuwanie dużej dokuczliwości szumów usznych często współwystępuje z zaburzeniami psychicznymi, szczególnie z depresją i zaburzeniami lękowymi w różnej postaci [23-27]. W literaturze przedmiotu, pod względem obecności doświadczanej depresji, osoby dzieli się na dwie grupy: doświadczające depresji aktualnie oraz na przestrzeni całego życia. Według badań [23-27] aktualnie, tj. w okresie przeprowadzania badań, na depresję cierpi od $28 \%$ do $60 \%$ osób z szumami usznymi. Najwyższa, wynosząca 78\%, częstotliwość występowania zaburzeń psychicznych na przestrzeni całego życia u osób z szumami usznymi raportowana jest w pracy Kröner-Herwig i wsp. [18]. Osoby z depresją wykazywały istotnie statystycznie wyższą różnicę $\mathrm{w}$ ocenie szumów usznych jako dokuczliwe $\mathrm{w}$ porównaniu $\mathrm{z}$ osobami bez depresji [25]. Interesujący wydaje się rezultat otrzymamy przez Zöger [23], z którego wynika, że tylko 9,5\% osób miało szumy uszne przed aktualnie istniejącymi zaburzeniami depresyjno-lękowymi. Natomiast tylko około 7\% osób dostrzega u siebie wymienione powyżej zaburzenia. Autorzy badań [23] zwrócili także uwagę na związek, jaki obecne problemy psychologiczne mają z oceną dokuczliwości szumów usznych. Doświadczany dystres z powodu szumów usznych związany jest zazwyczaj z wysokim poziomem odczuwanego cierpienia emocjonalnego i obniżonego nastroju. Czynniki emocjonalne mogą być istotnym predyktorem prognozującym cierpienie z powodu szumów usznych i stanowią duże wyzwanie dla specjalistów oferujących pomoc w ramach opieki zdrowotnej [23].

\section{Terapia poznawczo-behawioralna jako interwencja psychologiczna wobec osób cierpiących $\mathrm{z}$ powodu szumów usznych}

„Współczesna terapia poznawczo-behawioralna to cała grupa terapii odwołujących się do wspólnych założeń teoretycznych, zgodnie z którymi dysfunkcjonalne zachowania i emocje jednostki można wyjaśnić na podstawie teorii uczenia się i uwzględnienia mediacyjnej roli procesów poznawczych. Wspólne rozumienie celu terapii dotyczy skutecznej poprawy jakości życia pacjenta. Cel ten jest osiągany dzięki wykorzystaniu mechanizmów wynikających z założeń teoretycznych - poprzez modyfikację zachowań i sposobu myślenia. Odbywa się to w procesie terapii, którego zasadnicze cechy stanowią: oparcie na współpracy między terapeutą a pacjentem, zorientowanie na rozwiązanie problemu, skupienie na teraźniejszości, ograniczenie w czasie, a także zastosowanie adekwatnych technik terapeutycznych. Badania naukowe nad skutecznością terapii poznawczo-behawioralnej sprawiły, że obecnie jest ona najlepiej udokumentowaną formą leczenia metodami psychologicznymi i znajduje się w algorytmach postępowania terapeutycznego w leczeniu zaburzeń lękowych, afektywnych, schizofrenii, zaburzeń odżywiania, uzależnień i zaburzeń osobowości” [28].

Dotychczas wykazano, że terapia poznawczo-behawioralna ma związek z obniżeniem stresu, lęku, poziomu depresji u osób z szumami usznymi [14,29,30]. Pierwsze badania $\mathrm{z}$ zastosowaniem terapii poznawczo-behawioralnej u osób z szumami usznymi przeprowadzili w latach 80 . Scott, Lindberg i wsp. [31,32]. Terapie te skupiały się wokół technik poznawczych i behawioralnych w celu zwiększenia kontroli, uczenia strategii radzenia sobie z dokuczliwością szumów usznych oraz technik relaksacji. Wyniki badań pokazują znaczącą redukcję dyskomfortu związanego z szumami usznymi, poprawę nastroju oraz zwiększenie poczucia kontroli. W latach 90. Davis i wsp. [33] badali skuteczność indywidualnej terapii poznawczej i treningu relaksacyjnego $\mathrm{w}$ porównaniu $\mathrm{z}$ pasywnym odpoczynkiem. Wyniki badań nie wykazały żadnego znaczącego efektu terapeutycznego. Kröner-Herwig i wsp. [18] porównali skuteczność terapii poznawczo-behawioralnej z treningiem jogi (polegającym głównie na relaksacji). Terapia poznawczo-behawioralna obejmowała 10 sesji, a w nich: edukację, poznawcze techniki radzenia sobie/kontroli, trening uwagi, progresywną relaksację. Grupa jogi obejmowała relaksację, świadomość ciała, ćwiczenia (asany), ćwiczenia oddechowe. Wyniki badań pokazują, że w grupie, wobec której zastosowano terapię poznawczo-behawioralną, znacząco wzrósł poziom odczuwanej kontroli i zmniejszył się dyskomfort wywołany szumami usznymi oraz zwiększyła się zdolność do ich ignorowania w porównaniu z grupą osób ćwiczących jogę. Kolejne badanie [34] dotyczyło porównania terapii poznawczo-behawioralnej z terapią skoncentrowaną na rozwiązaniach (problemów). Oba podejścia

\footnotetext{
1. Katastroficzne myślenie jest definiowane jako tendencja do przeceniania wpływu warunków zewnętrznych, oczekiwanie głównie negatywnych konsekwencji (powiększanie ich), strach, martwienie się (ciągłe „przeżuwanie”), poczucie bezsilności i niemocy w poradzeniu sobie $\mathrm{z}$ daną sytuacją [30].
} 
okazały się skutecznie w zmniejszeniu stresu związanego z szumami usznymi.

Porównania dwóch form poznawczych interwencji u osób z szumami usznymi dokonali Henry i Wilson [35]. Osoby badane podzielili losowo na trzy grupy: 1 . Trening wyobrażeniowy i kontroli uwagi; 2. Modyfikacje poznawcze; 3. Połączenie treningu wyobrażeniowego i kontroli uwagi z modyfikacjami poznawczymi (grupa 1+2). Jako grupa kontrolna posłużyły osoby z listy oczekującej na wizytę w klinice szumów usznych. Wyniki badań pokazują znaczący wpływ treningu wyobrażeniowego i kontroli uwagi na modyfikację irracjonalnych przekonań w porównaniu z modyfikacjami poznawczymi.

Przeprowadzono również badania nad skutecznością terapii poznawczo-behawioralnej przez Internet [18,36-41]. Osoby badane otrzymywały w formie elektronicznej zbiór narzędzi (strategii) pomocnych w codziennym życiu. Narzędzia obejmowały m.in. różnego rodzaju ćwiczenia relaksacyjne, ćwiczenia koncentracji uwagi, pozytywne wizualizacje, dźwiękowe maskery, sposoby rozpoznawania negatywnych myśli i radzenia sobie $\mathrm{z}$ nimi, materiały dotyczące bezsenności i radzenia sobie $\mathrm{z}$ problemami związanymi z niedosłuchem oraz bezpieczną ekspozycję na dźwięki w przypadku nadwrażliwości słuchowej. Dodatkowo, w zależności od badań, osoby badane kontaktowały się z terapeutami przez e-mail bądź telefon. Wyniki badań wskazują na skuteczność terapii przez Internet w zakresie obniżenia: poziomu stresu, depresji, lęku, złagodzenia problemów ze snem, zmniejszenia odczuwanej głośności szumów usznych (choć rzeczywista głośność się nie zmieniła), unikania ich oraz poprawy jakości życia. Kaldo i wsp. [40] oraz Conrad i wsp. [41] porównali skuteczność terapii poznawczo-behawioralnej przez Internet $\mathrm{z}$,tradycyjnymi” grupami terapeutycznymi. Obie formy okazały się skuteczne w łagodzeniu dyskomfortu i zmianie dysfunkcjonalnych przekonań związanych z szumami usznymi, a ich efekty były stabilne w czasie. Autorzy badań podkreślają także, że terapia przez Internet łączy się $\mathrm{z}$ obniżeniem kosztów leczenia. Inne wyniki badań dotyczące terapii poznawczo-behawioralnej przez Internet uzyskali Abbot i wsp. [42]. Analiza wyników ich badań nie wykazała skuteczności terapii przez Internet w obniżeniu poziom stresu, depresji, lęku czy poprawie jakości życia.

Kröner-Herwing i wsp. [18] porównali kilka typów treningów i przeprowadzili badania $\mathrm{z}$ udziałem czterech grup: „tradycyjna terapia poznawczo-behawioralna” (11 sesji), "grupa edukacyjna" - informacje o szumach usznych z samopomocowymi strategiami radzenia sobie (2 sesje grupowe), „trening relaksacyjny” - wspomagany kasetami audio do autoterapii (4 sesje) oraz „grupa z listy oczekujących na wizytę”. Wyniki badań pokazują, że każda z proponowanych interwencji psychologicznych wpłynęła na poprawę jakości życia u osób z szumami usznymi. Najbardziej wyraźne zmiany odnotowano w zakresie radzenia sobie z dokuczliwością szumów usznych, wzrostu poczucia własnej skuteczności (kontroli), korzystania z relaksacji i zmniejszenia częstości występowania myśli i ocen dotyczących szumów usznych. Najskuteczniejszą formą interwencji psychologicznej okazała się terapia poznawczo-behawioralna, następnie edukacja i relaksacja. Wyniki badań [18,30,35-37] sugerują także, że połączenie różnych form interwencji, np. edukacji, porad dotyczących radzenia sobie z dokuczliwością szumów usznych, relaksacji i zastosowanie tła dźwiękowego wykorzystywanego w TRT (ang. Tinnitus Retraining Therapy), powoduje lepszy efekt terapeutyczny niż zastosowanie każdej z metod osobno.

Rezultaty powyżej przytaczanych badań [18,36-41], opisujących użyteczność materiałów do samopomocy, wydają się obiecujące. Być może skorzystanie $\mathrm{z}$ takich narzędzi przez osoby cierpiące z powodu szumów usznych przed uzyskaniem przez nie bardziej kompleksowego leczenia mogłoby je znacząco wesprzeć.

\section{Podsumowanie}

Osoby doświadczające znacznej dokuczliwości szumów usznych często zmagają się również z problemami natury psychologicznej. Wśród najczęściej wymienianych problemów podaje się depresję, zaburzenia lękowe, bezsenność, zaburzenia koncentracji uwagi oraz podwyższony poziom odczuwanego stresu. Dokuczliwość szumów usznych pozostaje w związku z pracą zawodową, funkcjonowaniem społecznym czy spędzaniem czasu wolnego. Sfera poznawcza, myśli i przekonania dotyczące szumów usznych oraz nadawane im znaczenie wydaja się być związane $\mathrm{z}$ odczuwaniem ich większej dokuczliwości. Osobom cierpiącym z powodu szumów usznych wychodzi naprzeciw terapia poznawczo-behawioralna $\mathrm{z}$ całym spektrum narzędzi dostosowanych do zgłaszanych problemów. Wyniki badań pokazują, że terapia ta jest zazwyczaj skuteczną interwencją psychologiczną wobec osób cierpiących z powodu szumów usznych.

Publikacja powstała $w$ zwiazku $z$ realizacja projektu pn. „Zintegrowany system narzędzi do diagnostyki i telerehabilitacji schorzeń narząów zmysłów (słuchu, wzroku, mowy, równowagi, smaku, powonienia)" INNOSENSE, wspótfinansowanego przez Narodowe Centrum Badań i Rozwoju w ramach Programu STRATEGMED.

\section{Piśmiennictwo:}

1. Bartnik G. Szumy uszne - fakty istotne klinicznie. Mag Otolaryngol, 2003; II, 3(7): 57-72.

2. Stephens SDG. The treatment of tinnitus - a historical perspective. J Laryngol Otol, 1984; 98: 963-72.

3. Dietrich S. Earliest historic reference of 'tinnitus' is controversial. J Laryngol Otol, 2004; 118: 487-8.

4. Baguley DM, Mc Ferran DJ. Tinnitus in childhood. Int J Otorhinolaryngol, 1999; 49: 99-105.
5. Fabijańska A, Rogowski M, Bartnik G, Skarżyński H: Epidemiology of tinnitus and hyperacusis in Poland. Proceedings of the Sixth International Tinnitus Seminar, Sixth International Tinnitus Seminar Cambridge UK, September 5-9, 1999; 569-71.

6. Hoffmann HJ, Reed GW. Epidemiology of tinnitus. W: Snow JB, red. Tinnitus: Theory and management. BC Decker: Hamilton; 2004, 16-41. 
7. Erlandsson SI, Holgers KM. The impact of perceived tinnitus severity on health-related quality of life with aspects of gender. Noise Health, 2001; 3: 39-51.

8. Andersson G, Vretblad P, Larsen HC, Lyttkens L. Longitudinal follow-up of tinnitus complaints. Arch Otolaryngol Head Neck Surg, 2001; 127: 175-9.

9. Van Veen ED, Jacobs JB, Bensing JM. Assessment of distress associated with tinnitus. The J Laryngol and Otol, 1998; 112: 258-63.

10. Gomaa MA, Elmagd MH, Elbadry MM, Kader RM. Depression, Anxiety and Stress Scale in patients with tinnitus and hearing loss. Eur Arch Otorhinolaryngol, 2014; 271: 2177-84.

11. Langenbach M, Olderog M, Michel O, Albus C, Kohle K. Psychosocial and personality predictors of tinnitus-related distress. Gen Hosp Psychiatry, 2005; 27: 73-7.

12. Heinecke K, Weise C, Schwarz K, Rief W. Physiological and psychological stress reactivity in chronic tinnitus. J Behav Med, 2008; 31: 179-88.

13. El Refaire A, Davis A, Kayan A, Baskill JL, Lovell E, Spencer H. Characteristics of tinnitus and related quality of life in people who attend at tinnitus clinic. Proceedings of the Sixth International Tinnitus Seminar 1999, Sixth International Tinnitus Seminar Cambridge UK, September 5-9, 1999; 560-1.

14. Andersson G, Lyttkens L. A meta-analytic review of psychological treatments for tinnitus. Br J Audiol, 1999; 33(4): 201-10.

15. Stevens C, Walker G, Boyer M, Gallagher M. Severe tinnitus and its effect on selective and divided attention. Int J Audiology, 2007; 46(5): 208-16.

16. Rossiter S, Stevens C, Walker G. Tinnitus and its effect on working memory and attention. J Speech Lang Hear Res, 2006; 49: $150-60$.

17. Weise C, Hesser H, Andersson G, Nyenhuis N, Zastrutzki S, Kröner-Herwig B i wsp. The role of catastrophizing in recent onset tinnitus: Its nature and association with tinnitus distress and medical utilization. Int J Audiol, 2013; 52: 177-88.

18. Kröner-Herwig B, Frenzel A, Fritsche G, Schilkowsky G, Esser G. The management of chronic tinnitus: Comparison of an outpatient cognitive-behavioral group training to minimal-contact interventions. J Psychosom Res, 2003; 54: 381-9.

19. Andersson G, McKenna L. The role of cognition in tinnitus. Acta Otolaryngol Suppl, 2006; 556: 39-43.

20. Zachriat C, Kröner-Herwig B. Treating chronic tinnitus: Comparison of cognitive-behavioural and habituation-based treatments. Cogn Behav Ther, 2004; 33: 187-98.

21. Cima R, Crombez G, Vlaeyen JW. Catastrophizing and fear of tinnitus predict quality of life in patients with chronic tinnitus. Ear Hear, 2011; 32: 634-41.

22. Holgers KM, Erlandsson SI, Barreñas ML. Predictive factors for the severity of tinnitus. Audiology, 2000; 39(5): 284-91.

23. Zöger S, Svedlund J, Holgers KM. Psychiatric disorders in tinnitus patients without severe hearing impairment: 24 month follow-up of patients at an audiological clinic. Audiology, 2001; 40(3): 133-40.

24. Lewandowska M, Niedziałek I, Milner R, Ganc M, Skarżyński H. Wpływ poziomu lęku i depresyjnych zaburzeń nastroju na uciążliwość obustronnych, subiektywnych szumów usznych - badania pilotażowe. Now Audiofonol, 2014; 3(4): 20-7.

25. Folmer RL, Griest SE, Meikle MB, Martin WH. Tinnitus severity, loudness and depression. Otolaryngol Head Neck Surg, 1999; 121: 48-51.
26. Meikle MB, Vernon J, Johnson RM. The perceived severity of tinnitus. Otolaryngol Head Neck Surg, 1984; 92: 689-96.

27. Malakouti SK, Nojomi M, Mahmoudian S, Alifattahi N, Salehi M. Comorbidity of chronic tinnitus and mental disorders. Int Tinnitus J, 2001; 16(2), 118-22.

28. Popiel A, Pragłowska E. Psychoterapia poznawczo-behawioralna - praktyka oparta na badaniach empirycznych. Psychiatria w Praktyce Klinicznej, 2009; 2(3): 146-55.

29. Andersson G. Psychological aspects of tinnitus and the application of cognitive-behavioral therapy. Clin Psychol Rev, 2002; 22(7): 977-90.

30. Hesser H, Weise C, Westin VZ, Andersson G. A systematic review and meta-analysis of randomized controlled trials of cognitive behavioral therapy for tinnitus distress. Clin Psychol Rev, 2011; 31(4): 545-53.

31. Scott B, Lindberg P, Lyttkens L, Melin L. Psychological treatment of tinnitus. An experimental group study. Scand Audiol, 1985; 14(4): 223-30.

32. Lindberg P, Scott B, Melin L, Lyttkens L. The psychological treatment of tinnitus: an experimental evaluation. Behav Res Ther, 1989; 27(6): 593-603.

33. Davies S, McKenna L, Hallam RS. Relaxation and cognitive therapy: a controlled trial in chronic tinnitus. Psychol Health, 1995; 10(2): 129-43.

34. Wise K, Rief W, Goebel G. Meeting the expectations of chronic tinnitus patients: comparison of a structured group therapy program for tinnitus management with a problem-solving group. J Psychosom Res, 1998; 44(6): 681-5.

35. Henry JL, Wilson PH. The Psychological Management of Tinnitus: Comparison of a Combined Cognitive Educational Program, Education Alone and a Waiting - List Control. Int Tinnitus J, 1996; 2: 9-20.

36. Andersson G, Melin L, Hagnebo C, Scott B, Lindberg P. A review of psychological treatment approaches for patients suffering from tinnitus. Ann Behav Med, 1995; 17(4): 357-66.

37. Henry JL, Wilson PH. An evaluation of two types of cognitive intervention in the management of chronic tinnitus. Scand J Behav Ther, 1998; 27: 156-66.

38. Hesser H, Gustafsson T, Lunden C i wsp. A randomized controlled trial of Internet-delivered cognitive behavior therapy and acceptance and commitment therapy in the treatment of tinnitus. J Consult Clin Psychol, 2012; 80(4): 649-61.

39. Andersson G, Stromgren T, Strom L, Lyttkens L. Randomized controlled trial of internet-based cognitive behavior therapy for distress associated with tinnitus. Psychosom Med, 2001; 64(5): 810-16.

40. Kaldo V, Levin S, Widarsson J, Buhrman M, Larsen HC, Andersson G. Internet versus group cognitive-behavioral treatment of distress associated with tinnitus: a randomized controlled trial. Behav Ther, 2008; 39(4): 348-59.

41. Conrad I, Kleinstäuber M, Jasper K, Hiller W, Andersson G, Weise $\mathrm{C}$. The changeability and predictive value of dysfunctional cognitions in Cognitive Behavior Therapy for chronic tinnitus. Int J Behav Med, 2015; 22(2): 239-50.

42. Abbott JA, Kaldo V, Klein B i wsp. A cluster randomised trial of an internet-based intervention program for tinnitus distress in an industrial setting. Cogn Behav Ther, 2009; 38(3): 162-73. 